\title{
Desempenho produtivo e nutricional de sorgo forrageiro consorciado com soja em doses de nitrogênio
}

\author{
Rodrigo Ribeiro Fidelis*, Luiz Antonio Menezes Gonzaga, \\ Rubens Ribeiro da Silva, Carlos Augusto Oliveira de Andrade
}

Universidade Federal do Tocantins, Gurupi, TO, Brasil

*Autor correspondete, e-mail: fidelisrr@mail.uft.edu.br

\begin{abstract}
Resumo
O objetivo deste trabalho foi avaliar o desempenho produtivo e nutricional de sorgo forrageiro consorciado com soja e submetido a doses de nitrogênio. O delineamento utilizado foi em blocos ao acaso com quatro repetições em esquema fatorial $(6 \times 2+1)$ sendo seis doses de nitrogênio $(0,20$,

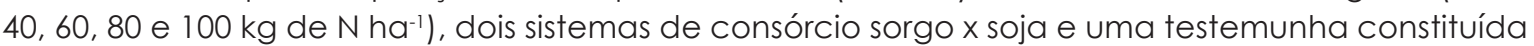
de sorgo solteiro com aplicação de $100 \mathrm{~kg}$ de $\mathrm{N} \mathrm{ha}^{-1}$. As variáveis avaliadas foram produtividade de matéria fresca e seca do sorgo, proteína bruta do sorgo, produtividade de matéria fresca e seca do consórcio, proteína bruta do consórcio e índice de eficiência de proteína bruta. Maiores doses de $\mathrm{N}$ aplicadas em cobertura no consórcio sorgo x soja, elevam a produtividade e qualidade nutricional da forragem em relação ao monocultivo. O consórcio de sorgo com duas linhas de soja proporciona maiores produtividades de matéria fresca, matéria seca e proteína bruta. O consórcio com uma e duas linhas de soja proporciona economia de $40 \%$ e $60 \%$ de nitrogênio na produção de proteína bruta em relação ao monocultivo de sorgo, respectivamente.
\end{abstract}

Palavras-chave: adubação mineral, Glicine max, produção de forragem, silagem, Sorghum bicolor.

\section{Productive and nutritional performance of forage sorghum intercropped with soybean according to nitrogen doses}

\begin{abstract}
The objective of this study was to evaluate the nutritional and productive performance of forage sorghum in an intercropping with soybean submitted to nitrogen doses. The experiment was in blocks with a complete randomized design, with four repetitions in a factorial arrangement $(6 \times 2+1)$, with six doses of nitrogen $\left(0,20,40,60,80\right.$ e $\left.100 \mathrm{~kg} \mathrm{de} \mathrm{N} \mathrm{ha}^{-1}\right)$, in two systems, being the intercropping of sorghum $x$ soybean and one control with only sorghum with an application of $100 \mathrm{~kg} \mathrm{de} \mathrm{N} \mathrm{ha-}^{-1}$. The variables studied were sorghum dry and fresh matter productivity, crude protein of sorghum, fresh matter productivity for the intercropping and protein efficiency index. Higher doses of $\mathrm{N}$ applied as cover on the sorghum $x$ soybean intercropping increased the quality and the productivity of the forage, when compared to the monoculture. The sorghum intercropping with two lines of soybean provides higher productivities of fresh matter, dry matter and crude protein. The intercropping with one and two lines of soybean provides a saving of $40 \%$ and $60 \%$, respectively, of nitrogen on the production of crude protein when compared to monoculture.
\end{abstract}

Keywords: mineral fertilizers, Glycine max., forage production, silage, Sorghum bicolor. 
Fidelis et al. (2016) / Desempenho produtivo e nutricional de sorgo forrageiro...

\section{Introdução}

O sorgo forrageiro (Sorghum bicolor L. Moench) possui importante papel no cenário agropecuário, onde tem sido muito utilizado na alimentação animal. Essa forrageira tem se destacado por apresentar características que a coloca entre as melhores gramíneas para o processo de ensilagem, produzindo em quantidades satisfatória massa verde e massa seca, além de uma quantidade significativa de proteína bruta, principalmente quando consorciado com a soja.

O consórcio entre as culturas soja e sorgo é uma alternativa de produção de forragem que vem sendo bastante estudada no cerrado brasileiro e, tem apresentados resultados satisfatórios em produtividade e qualidade nutricional (Rezende et al., 2010; Alcantara et al., 2011). Entretanto, a maioria das áreas de produção de forragem está destinada a pastagens naturais, as quais apresentam baixo valor nutritivo devido principalmente às condições de solo e manejo ainda deficientes, sendo necessário o desenvolvimento de técnicas de manejo e adubação mais consistentes possibilitando aumentar a produtividade por unidade de área.

Com exceção da soja, as espécies agrícolas cultivadas no cerrado demandam altas quantidades de nitrogênio para uma produtividade competitiva. Considerando-se que os fertilizantes nitrogenados vêm passando por frequentes reajustes de preços e são dependentes de oscilações cambiais, pois grande parte é importada, estes representam uma parcela significativa e crescente no custo de produção (Lange et al., 2014). Dessa forma, a consorciação de gramíneas com leguminosas fixadoras de nitrogênio por processos simbióticos com bactérias é uma alternativa para reduzir os custos de produção e melhorar a produtividade das culturas (Barcelos et al., 2008).

Objetivou-se com este trabalho avaliar o desempenho produtivo e nutricional de sorgo forrageiro consorciado com soja e submetido a doses de nitrogênio.

\section{Material e Métodos}

O experimento foi conduzido no campo experimental da Universidade Federal do Tocantins, no município de Gurupi, localizado na região sul do estado do Tocantins, a 1 144'51,06" de latitude Sul e 49०03'13,62" de longitude Oeste e em uma altitude de $277 \mathrm{~m}$. O clima da região é do tipo BIWA'a', úmido com moderada deficiência hídrica (Köppen, 1948).

O experimento foi instalado em um LATOSSOLO AMARELO distrófico (Embrapa, 1999). O delineamento utilizado foi em blocos ao acaso com quatro repetições em sistema fatorial $6 \times 2+1$, sendo seis doses de nitrogênio $\left(0,20,40,60,80\right.$ e $100 \mathrm{~kg}$ de $\left.\mathrm{N} \mathrm{ha}^{-1}\right)$, duas formas de consórcio entre sorgo e soja ( 1 linha e 2 linhas de soja), mais um tratamento de sorgo solteiro com aplicação de $100 \mathrm{~kg}$ de $\mathrm{N} \mathrm{ha}^{-1}$. Tanto a soja quanto o sorgo foram implantadas com densidade média de 12 plantas por metro linear, onde a soja foi plantada nas entrelinhas do sorgo, o qual foi semeado com espaçamento de 0,8 m, as parcelas apresentavam $5 \mathrm{~m}$ de comprimento com três linhas de sorgo.

A cultivar de sorgo utilizada foi o híbrido forrageiro BRS 655 com germinação média de $80 \%$ e pureza de $98 \%$ e, a de soja foi a variedade P98C81 sendo submetida à inoculação com os microorganismos Bradyrhizobium japonicum, Semia 5079 e Semia 5080, na dose de 150g para $50 \mathrm{~kg}$ de sementes.

A adubação de base para o sorgo e a soja foi feita de acordo com a exigência de cada cultura e de acordo com análise de solo, a qual apresentou os seguintes resultados: $\mathrm{pH}$ em água $=5,13 ; \mathrm{P}=4,42 \mathrm{mg} \mathrm{dm}^{-3} ; \mathrm{K}=16,6 \mathrm{mg}$ $\mathrm{dm}^{-3} ; \mathrm{Ca}=1,18 \mathrm{cmol}_{\mathrm{c}} \mathrm{dm}^{-3} ; \mathrm{Mg}=1,80 \mathrm{cmol}_{\mathrm{c}} \mathrm{dm}$ 3; $\mathrm{Al}=0,08 \mathrm{cmol}_{\mathrm{c}} \mathrm{dm}^{-3} ; \mathrm{H}+\mathrm{Al}=3,04 \mathrm{cmol}_{\mathrm{c}} \mathrm{dm}^{-3}$; M.O. = 1,94 dag $\mathrm{dm}^{-3} ;$ Areia $=735 \mathrm{~g} \mathrm{dm}^{-3}$; Silte $=72,6 \mathrm{~g} \mathrm{dm}^{-3}$ e Argila $=194,5 \mathrm{~g} \mathrm{dm}^{-3}$ (Embrapa, 1997). Foram aplicados manualmente na linha da cultura do sorgo $707 \mathrm{~kg} \mathrm{ha}^{-1}$ de superfosfato simples e $259 \mathrm{~kg} \mathrm{ha}^{-1}$ de cloreto de potássio e, para a cultura da soja aplicou-se, $940 \mathrm{~kg} \mathrm{ha}^{-1}$ de superfosfato simples e $207 \mathrm{~kg} \mathrm{ha}^{-1}$ de cloreto de potássio na linha. A adubação nitrogenada foi feita com uréia, apenas em cobertura aos 15 dias e aos 25 dias após o plantio.

A colheita do sorgo foi determinada em função do ponto de colheita da soja seguindo recomendação de Rezende et al. (2001). 
As características agronômicas do sorgo forrageiro avaliadas foram: produtividade de matéria fresca ( $\left.t \mathrm{ha}^{-1}\right)$, estimada com a pesagem de 10 plantas após serem trituradas; produtividade de matéria seca $\left(\dagger \mathrm{ha}^{-1}\right)$, estimada através de subamostra de $300 \mathrm{~g}$ de massa de matéria fresca submetida à secagem em estufa a $65^{\circ} \mathrm{C}$ até peso constante; proteína bruta (t ha '), determinada a partir da análise de nitrogênio pelo Método Kjeldahl (Bremner \& Mulvaney, 1982).

A produtividade de matéria fresca, produtividade de matéria seca e proteína bruta do consórcio foram determinadas somando os resultados obtidos para o sorgo e a soja. Foi também determinado o índice de eficiência de proteína bruta.

As variáveis da soja utilizadas para a determinação da produtividade de matéria fresca, produtividade de matéria seca e proteína bruta do consórcio seguiram a mesma metodologia adotada para o sorgo forrageiro, exceto a produtividade de matéria fresca que foi estimada com a pesagem de 20 plantas após serem trituradas.

O índice de eficiência de proteína bruta (IE) em porcentagem foi calculado em comparação com a testemunha (sorgo solteiro com aplicação de $100 \mathrm{~kg}$ de $\mathrm{N} \mathrm{ha}^{-1}$ ) pela fórmula apresentada abaixo, onde o tratamento foi tido como o valor referência, os valores negativos encontrados pela fórmula mostraram o quanto o tratamento foi menos eficiente em relação à testemunha e os valores positivos mostraram o quanto o tratamento foi superior à testemunha.

$\mathrm{IE}=\underline{\text { Tratamento-Testemunha }} \times 100$ Tratamento

Procedeu-se análises de variância, seguida pelo teste de médias de Tukey para as variáveis qualitativas e, análises de regressão para as variáveis quantitativas significativas a $p<0,05$ pelo teste $F$, utilizando o aplicativo computacional SISVAR (Ferreira, 2008).

\section{Resultados e Discussão}

Para a produtividade de matéria fresca do sorgo (Tabela 1) notou-se que os tratamentos em consórcio com as maiores doses de nitrogênio (80 e $100 \mathrm{~kg} \mathrm{ha}^{-1}$ ) tanto com uma e duas linhas de soja foram superiores a testemunha, porém, o consórcio com uma e duas linhas não diferiram entre si. É importante observar que no consórcio com duas linhas de soja apenas o tratamento com zero de $\mathrm{N}$ não diferiu da testemunha, todos os demais tratamentos foram superiores ao sorgo solteiro com aplicação de $100 \mathrm{~kg}$ de $\mathrm{N} \mathrm{ha}^{-1}$.

A produtividademédia de matéria fresca, segundo Alcântara et al. (2011) é incrementada significativamente no consórcio. Esses autores observaram que o sorgo consorciado com soja na entrelinha obteve produtividade média de $34,12+$ ha $^{-1}$ ao passo que em monocultivo 31,81 $\mathrm{tha}^{-1}$.

É importante ressaltar que o tratamento testemunha foi submetido à dose de $100 \mathrm{~kg}$ de $\mathrm{N}$ $\mathrm{ha}^{-1}$, sendo igual às maiores doses de nitrogênio aplicado nos dois sistemas de consórcio, sendo o diferencial apenas a presença da soja, o que fornece embasamento para afirmar que a maior produtividade dos sistemas consorciados pode estar relacionado com a disponibilização de nitrogênio pela soja obtido do processo simbiótico. De acordo com Cantarutti \& Boddey (1997), parte do nitrogênio fixado pela leguminosa pode ser transferido para a gramínea associada por meio de produtos nitrogenados excretados pelas raízes, por fluxo de nitrogênio através de hifas de fungos micorrízicos e por reabsorção do nitrogênio volatilizado ou lixiviado da folhagem da leguminosa.

A produtividade matéria seca do sorgo (Tabela 1) apresentou-se superior nos tratamentos de sorgo em consórcio com duas linhas de soja e com aplicação de 80 e 100 kg de $\mathrm{N} \mathrm{ha}^{-1}$ em relação aos demais tratamentos. Observou-se nos tratamentos com duas linhas de soja, que apenas o tratamento com zero de $\mathrm{N}$ não se apresentou superior à testemunha, evidenciando a melhor produtividade de matéria seca no sistema consorciado com duas linhas de soja e com aplicação a partir de $20 \mathrm{~kg}$ de $\mathrm{N} \mathrm{ha}^{-1}$. O ganho de produtividade de matéria seca foi evidente no sistema consorciado chegando a atingir 3, $16 \mathrm{tha}^{-1}$, sendo dessa forma mais vantajoso para o processo de ensilagem.

A produtividade de proteína bruta do sorgo (Tabela 1) nos sistemas consorciados, tanto com uma e duas linhas de soja e com as 
Fidelis et al. (2016) / Desempenho produtivo e nutricional de sorgo forrageiro...

maiores doses de nitrogênio $(80$ e $100 \mathrm{~kg}$ de $\mathrm{N}$ $\mathrm{ha}^{-1}$ com uma linha de soja e 60, 80 e $100 \mathrm{~kg}$ de $\mathrm{N} \mathrm{ha}^{-1} \mathrm{com}$ duas linhas de soja) foram superiores ao tratamento testemunha mostrando que o consórcio proporcionou além de produtividade, qualidade nutricional com aumento nos teores de proteína bruta, chegando a ser superior a testemunha em $0,43+\mathrm{ha}^{-1}$ para o sistema consorciado com duas linhas de soja e com aplicação de $100 \mathrm{~kg}$ de $\mathrm{N} \mathrm{ha}^{-1}$. Em trabalho semelhante, Alcântara et al. (2011) concluíram que o consórcio sorgo-soja proporciona maior produtividade de proteína bruta e, Rezende et al. (2010) concluíram que o sistema em consórcio sorgo-soja apresentou forragem mais rica em nutrientes em relação ao monocultivo do sorgo.

Tabela 1. Produtividades médias de matéria fresca do sorgo (MMF), matéria seca do sorgo (MMS), proteína bruta do sorgo (PB), matéria fresca do consórcio (MMF), matéria seca do consórcio (MMS) e proteína bruta do consórcio (PB), Gurupi-TO, 2012

\begin{tabular}{|c|c|c|c|c|c|c|}
\hline \multirow{3}{*}{ TRATAMENTOS } & \multicolumn{3}{|c|}{ Sorgo } & \multicolumn{3}{|c|}{ Consórcio } \\
\hline & MMF & MMS & $\mathrm{PB}$ & MMF & MMS & PB \\
\hline & & & 069 cA & & & \\
\hline Sorgo solteiro $+100 \mathrm{~kg}$ de $\mathrm{N}$ & $28,57 \mathrm{dA}$ & $9,63 \mathrm{dA}$ & $0,69 \mathrm{cA}$ & 28,57 eA & $9,63 \mathrm{dA}$ & 0,69 eA \\
\hline Sorgo-soja 1 linha $+0 \mathrm{~kg}$ de $\mathrm{N}$ & $27,08 \mathrm{~dB}$ & $9,16 \mathrm{~dB}$ & $0,50 \mathrm{~dB}$ & $29,57 \mathrm{eA}$ & $10,42 \mathrm{dA}$ & $0,70 \mathrm{eA}$ \\
\hline Sorgo-soja 1 linha $+20 \mathrm{~kg}$ de $\mathrm{N}$ & $28,58 \mathrm{~dB}$ & $9,64 \mathrm{~dB}$ & $0,52 \mathrm{~dB}$ & $31,01 \mathrm{dA}$ & $10,83 \mathrm{cA}$ & $0,72 \mathrm{eA}$ \\
\hline Sorgo-soja 1 linha $+40 \mathrm{~kg}$ de $\mathrm{N}$ & $30,79 \mathrm{CB}$ & $10,37 \mathrm{CB}$ & $0,66 \mathrm{CB}$ & $33,15 \mathrm{cA}$ & $11,41 \mathrm{cA}$ & $0,86 \mathrm{dA}$ \\
\hline Sorgo-soja 1 linha $+60 \mathrm{~kg}$ de $\mathrm{N}$ & $31,09 \mathrm{CB}$ & $10,41 \mathrm{CB}$ & $0,68 \mathrm{CB}$ & $34,12 \mathrm{cA}$ & $11,70 \mathrm{cA}$ & $0,88 \mathrm{dA}$ \\
\hline Sorgo-soja 1 linha $+80 \mathrm{~kg}$ de $\mathrm{N}$ & $36,86 \mathrm{aB}$ & $11,80 \mathrm{bB}$ & $0,88 \mathrm{bB}$ & $39,83 \mathrm{aA}$ & $13,10 \mathrm{bA}$ & $1,08 \mathrm{bA}$ \\
\hline Sorgo-soja 1 linha +100 kg de $N$ & $37,88 \mathrm{aB}$ & $11,42 \mathrm{bB}$ & $0,88 \mathrm{bB}$ & $40,49 \mathrm{aA}$ & $12,56 \mathrm{bA}$ & $1,08 \mathrm{bA}$ \\
\hline Sorgo-soja 2 linhas + 0 kg de $N$ & $28,65 \mathrm{~dB}$ & $9,09 \mathrm{~dB}$ & $0,51 \mathrm{~dB}$ & $32,40 \mathrm{dA}$ & $10,76 \mathrm{dA}$ & $0,71 \mathrm{eA}$ \\
\hline Sorgo-soja 2 linhas $+20 \mathrm{~kg}$ de $\mathrm{N}$ & $30,56 \mathrm{CB}$ & $10,18 \mathrm{CB}$ & $0,74 \mathrm{CB}$ & $34,07 \mathrm{cA}$ & $11,70 \mathrm{cA}$ & $0,93 \mathrm{cA}$ \\
\hline Sorgo-soja 2 linhas $+40 \mathrm{~kg}$ de $\mathrm{N}$ & $31,22 \mathrm{CB}$ & $10,36 \mathrm{CB}$ & $0,77 \mathrm{CB}$ & $35,16 \mathrm{CA}$ & $12,23 \mathrm{cA}$ & $0,97 \mathrm{cA}$ \\
\hline Sorgo-soja 2 linhas $+60 \mathrm{~kg}$ de $\mathrm{N}$ & $34,03 \mathrm{bB}$ & $11,74 \mathrm{bB}$ & $0,85 \mathrm{bB}$ & $37,26 \mathrm{bA}$ & $13,58 \mathrm{bA}$ & $1,05 \mathrm{bA}$ \\
\hline Sorgo-soja 2 linhas $+80 \mathrm{~kg}$ de $\mathrm{N}$ & $36,77 \mathrm{aB}$ & $12,50 \mathrm{aB}$ & $0,93 \mathrm{bB}$ & $41,19 \mathrm{aA}$ & $14,42 \mathrm{aA}$ & $1,13 \mathrm{bA}$ \\
\hline Sorgo-soja 2 linhas $+100 \mathrm{~kg}$ de $\mathrm{N}$ & $38,18 \mathrm{aB}$ & $12,79 \mathrm{aB}$ & $1,12 a B$ & $40,29 \mathrm{aA}$ & $13,89 \mathrm{aA}$ & $1,32 \mathrm{aA}$ \\
\hline Média & 31,78 & 10,70 & 0,75 & 35,16 & 12,02 & 0,93 \\
\hline$C \vee(\%)$ & 3,31 & 5,92 & 7,87 & 3,05 & 5,31 & 6,32 \\
\hline
\end{tabular}

A proteína bruta e o índice de eficiência de proteína bruta do sorgo (Figura 1) apresentaram respostas lineares crescentes ao incremento de nitrogênio, sendo significativos a $p<0,01$ nos dois sistemas de consórcio, corroborando com Fernandes et al. (2009) que observaram efeitos lineares positivos na proteína bruta de silagem de sorgo com a aplicação de doses de uréia.

O índice de eficiência de proteína bruta (Figura 1) mostrou que o sistema em consórcio com duas linhas de soja foi mais eficiente que o sistema com uma linha de soja. Observouse que a proteína bruta do sorgo forrageiro no sistema com uma linha igualou-se ao tratamento testemunha com a aplicação de aproximadamente $60 \mathrm{~kg}$ de $\mathrm{N} \mathrm{ha}^{-1}$, enquanto - sistema em consórcio com duas linhas correspondeu ao tratamento testemunha com a aplicação abaixo de $40 \mathrm{~kg}$ de $\mathrm{N} \mathrm{ha}^{-1}$, o que geraria dessa forma, economia de 40 e $60 \%$ do mineral, respectivamente, para produção de proteína bruta.

\section{Conclusões}

Com base nesses resultados pode-se concluir que a qualidade nutricional nos dois sistemas de consórcio proporcionou economia de $\mathrm{N}$, sendo o sistema com duas linhas de soja mais eficiente, proporcionando melhor valor nutricional da silagem em relação ao monocultivo, corroborando com Rezende et al. (2010) que verificaram melhoria na qualidade da forragem comparando o consórcio sorgosoja em relação ao monocultivo.

Nesse contexto, maiores doses de $\mathrm{N}$ aplicadas em cobertura no consórcio sorgo $x$ soja, elevam a produtividade e a qualidade nutricional da forragem em relação ao monocultivo. Enquanto que, o consórcio de sorgo com duas linhas de soja proporciona maiores produtividades de matéria fresca, matéria seca e proteína bruta. 

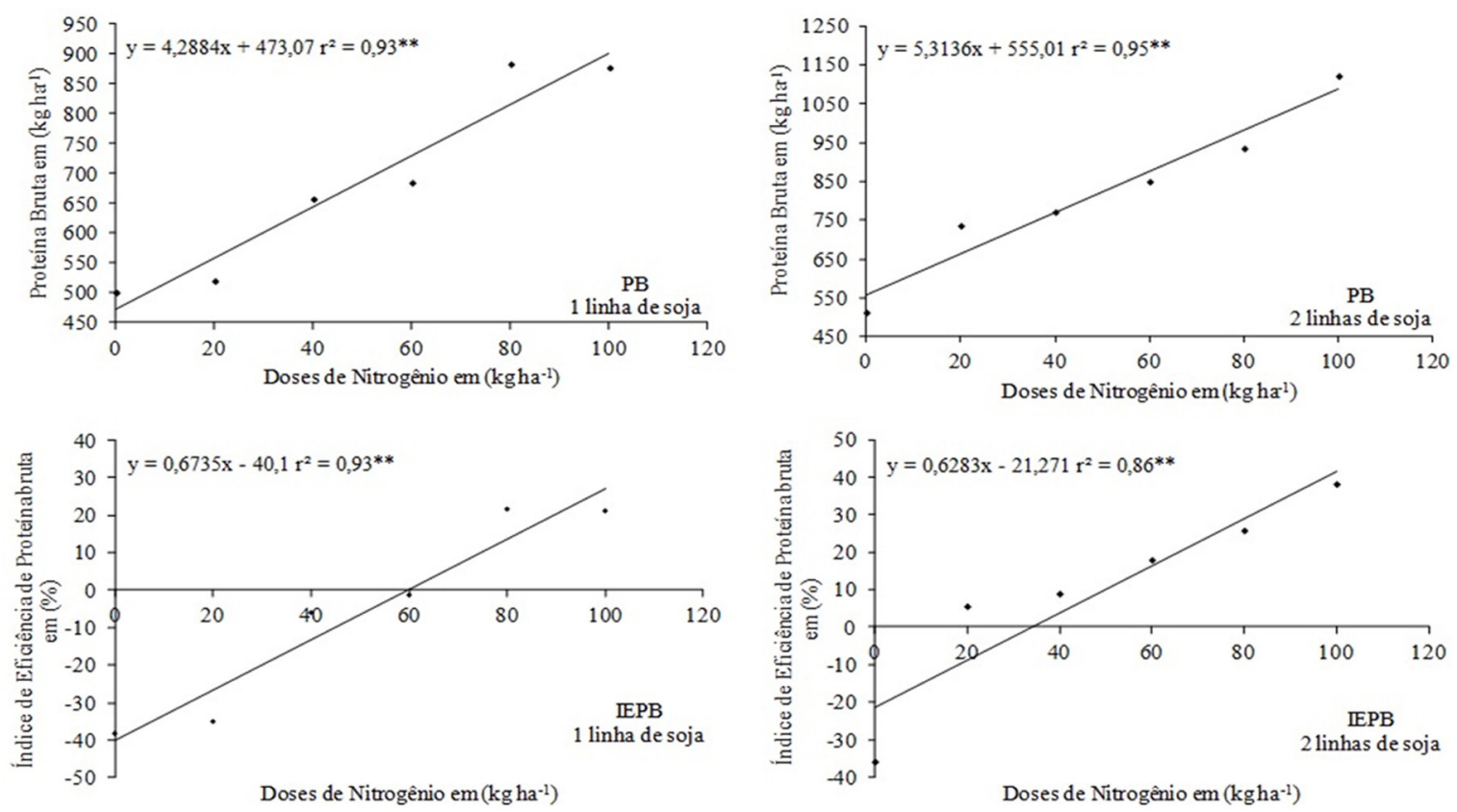

Por sua vez, o consórcio com uma ou com duas linhas de soja proporciona economia de $40 \%$ e $60 \%$ de nitrogênio na produção de proteína bruta em relação ao monocultivo de sorgo, respectivamente.

\section{Referências}

Alcantara, H.P., Rezende, P.M., Carvalho, E.R., Passos, A.M.A., Botrel, E.P. 2011. Consórcio sorgo-soja. XVI. Cortes, épocas de semeadura e cultivares de soja na produção de forragem. Revista Ciência Agronômica 42: 116-124.

Barcellos, A.O., Ramos, A.K.B., Vilela, L., Martha Junior, G.B. 2008. Sustentabilidade da produção animal baseada em pastagens consorciadas e no emprego de leguminosas exclusivas, na forma de banco de proteína, nos trópicos brasileiros. Revista Brasileira de Zootecnia 37: 51-67.

Bremner, J.M., Mulvaney, C.S. Total nitrogen. In: Page, A.L. 1982. ED Methods of soil analysis. Medison: American Society of Agronomy. 595p.

Cantarutti, R.B., Boddey, R.M. 1997. Transferência de nitrogênio das leguminosas para as gramíneas. In: Simpósio internacional sobre produção animal em pastejo. Departamento de Zootecnia, Viçosa, p. 431-445.

Empresa Brasileira de Pesquisa Agropecuária (EMBRAPA). 1997. Manual de métodos de análises de solo. 2. ed, Rio de Janeiro.

Empresa Brasileira de Pesquisa Agropecuária (EMBRAPA). Sistema brasileiro de classificação dos solos. 1999. Rio de Janeiro: EMBRAPA/CNPS, $412 \mathrm{p}$. 